\title{
GESTÃO DEMOCRÁTICA NA EDUCAÇÃO SUPERIOR PARA A DIFERENCIAÇÃO E ACESSIBILIDADE CURRICULAR
}

\author{
GESTIÓN DEMOCRÁTICA EN LA EDUCACIÓN SUPERIOR PARA LA \\ DIFERENCIACIÓN Y ACCESIBILIDAD CURRICULAR
}

\author{
DEMOCRATIC MANAGEMENT IN HIGHER EDUCATION FOR CURRICULAR \\ DIFFERENTIATION AND ACCESSIBILITY
}

\author{
André Henrique de LIMA $^{1}$ \\ Leonardo Santos Amâncio CABRAL ${ }^{2}$
}

RESUMO: A Gestão Democrática na Educação Superior, para além da gestão de recursos humanos, financeiros, tecnológicos e materiais, prevê a interrelação da gestão pedagógica, do acesso ao currículo, da ação docente, dos resultados, dos espaços, das condutas e interações culturais. Contudo, as Instituições da Educação Superior (IES), tradicionalmente, tendem a subdividirem e a fragmentarem suas ações, distanciando-se da perspectiva da acessibilidade, a qual incita a interrelação cooperativa de elementos e práticas inclusivas concretas e alcançáveis. Assim, a presente pesquisa objetivou identificar possibilidades de práticas de gestão democrática na perspectiva da acessibilidade em uma IES, a partir do envolvimento de gestores, docentes e estudantes com e sem deficiência. Os resultados indicaram que, iniciativas para (des)construção sobre concepções de deficiência e de formação profissional, suscitaram a comunidade acadêmica a identificar e a questionar sobre diversas barreiras presentes no contexto acadêmico, baseando o planejamento de ações que fomentassem mudanças positivas nesse cenário.

PALAVRAS-CHAVE: Educação especial. Pessoas com deficiências. Currículo. Cooperação. Formação profissional.

RESUMEN: La gestión democrática en la educación superior, además de la gestión de recursos humanos, financieros, tecnológicos y materiales, proporciona la interrelación de la gestión pedagógica, el acceso al plan de estudios, la acción docente, los resultados, los espacios, las conductas y las interacciones culturales. Sin embargo, las Instituciones de Educación Superior (IES) han tendido tradicionalmente a subdividir y fragmentar sus acciones, distanciarse de la perspectiva de accesibilidad, lo que fomenta la interrelación cooperativa de elementos y prácticas inclusivos concretos y alcanzables. Por lo tanto, la presente investigación tuvo como objetivo identificar las posibilidades de las prácticas de gestión democrática en la perspectiva de accesibilidad en una IES, basada en la participación de gerentes, maestros y estudiantes con y sin discapacidad. Los resultados indicaron que, las iniciativas para la (des)construcción sobre las concepciones de la discapacidad y la

${ }^{1}$ Universidade Federal de São Carlos (UFSCAR), São Carlos - SP - Brasil. Graduando em Educação Especial. ORCID: http://orcid.org/0000-0002-9554-7150. E-mail: andrehdelima@gmail.com

${ }^{2}$ Universidade Federal de São Carlos (UFSCAR), São Carlos - SP - Brasil. Professor Adjunto no Departamento de Psicologia e no Programa de Pós-Graduação em Educação Especial. Doutorado em Educação Especial (UFSCAR). ORCID: http://orcid.org/0000-0003-3520-3687. E-mail: prof.leonardocabral@gmail.com

RPGE- Revista on line de Política e Gestão Educacional, Araraquara, v. 24, n. esp. 2, p. 1104-1117, set. 2020. e-ISSN: 1519-9029 
capacitación profesional, plantearon a la comunidad académica para identificar y cuestionar diversas barreras presentes en el contexto académico, basando la planificación de acciones que fomentan cambios positivos en este escenario.

PALABRAS CLAVE: Educación especial. Personas con discapacidades. Plan de estudios. Cooperación. Formación profesional.

ABSTRACT: Democratic Management in Higher Education, in addition to the management of human, financial, technological and material resources, provides for the interrelation of pedagogical management, access to curriculum, teaching action, results, spaces, conducts and cultural interactions. However, Higher Education Institutions (HEIs) have traditionally tended to subdivide and fragment their actions, distancing themselves from the perspective of accessibility, which encourages the cooperative interrelation of concrete and achievable inclusive elements and practices. Thus, the present research aimed to identify possibilities of democratic management practices in the perspective of accessibility in an HEI, based on the involvement of managers, teachers and students with and without disabilities. The results indicated that, initiatives for (de)construction on conceptions of disability and professional formation, raised the academic community to identify and question various barriers present in the academic context, basing the planning of actions that foster positive changes in this scenario.

KEYWORDS: Special education. Persons with disabilities. Curriculum. Cooperation. Professional formation.

\section{Introdução}

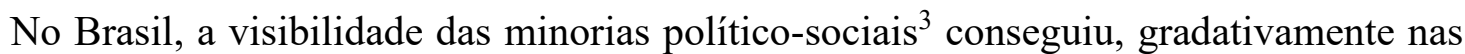
últimas décadas, ganhar maior notoriedade, ainda que em um moroso processo de legitimação de seus direitos formais e substanciais nos diversos contextos sociais.

Particularmente no que tange a democratização do acesso às esferas educacionais, esse cenário tem incitado discussões democráticas sobre as práticas e as teorias que tangenciam a gestão na perspectiva da orquestração da acessibilidade (KRAWCZYK, 1999; LIMA; CABRAL, 2018; EBERSOLD, 2020).

No âmbito das Instituições da Educação Superior (IES) brasileiras, as políticas de ações afirmativas, sobretudo na última década, tem culminado no aumento do índice de ingresso de pessoas com deficiências advindas de escolas públicas, sejam elas ou não com Transtorno do Espectro do Autismo (TEA), pretas, pardas ou indígenas (CABRAL, 2018).

${ }^{3}$ Sob uma perspectiva antropológica e político-social, faz referência “(...) aos subgrupos marginalizados, ou seja, minimizados socialmente no contexto nacional, podendo, inclusive, constituir uma maioria em termos quantitativos. Dessa forma, para ser objeto de tutela internacional, a minoria deve, necessariamente, ser caracterizada pela posição de não dominância que ocupa no âmbito do Estado em que vive” (MORENO, 2009, p.152).

RPGE- Revista on line de Política e Gestão Educacional, Araraquara, v. 24, n. esp. 2, p. 1104-1117, set. 2020. e-ISSN: 1519-9029 
Esses movimentos têm desafiado a comunidade científica, os diversos cenários e seus respectivos atores a identificarem e a dialogarem sobre possíveis caminhos para se concretizar a gestão democrática que, inclusive conceitualmente, apresenta consensos e dissensos (LÜCK, 2007; AGUIAR, 2016; OLIVEIRA; VASQUES-MENEZES, 2018; MACHADO; CORTE, 2020).

Ainda assim, fundamentando-se em autores como Bordignon e Gracindo (2000), Libâneo (2007), Araújo (2009) e Aguiar (2016) e Ebersold (2020), bem como em nossas vivências empíricas no âmbito da pesquisa, do ensino e da extensão, concebemos nossa compreensão de gestão democrática.

$\mathrm{Na}$ perspectiva da acessibilidade, biopsicossocial e interdisciplinar, a gestão democrática pode ser compreendida como a orquestração de ações cooperativas e multivetoriais que envolvam gestores, docentes, servidores técnicos e administrativos e discentes, das diversas unidades institucionais, para a identificação de possibilidades que legitimem o direito cidadão do ingresso, da permanência, da formação e da transição ao mercado de trabalho, reconhecendose as identidades e diferenças das minorias político-sociais.

A premissa, portanto, é a de transversalizar a coletivização dos processos de: a) elaboração e implementação de políticas institucionais; b) ações, condutas e necessidades dos recursos humanos; c) provisão de infraestrutura, recursos financeiros, materiais e tecnológicos; d) interações socioculturais e construção de linguagens; e) planejamento e desenvolvimento de ações, valendo-se da gestão dos tempos e espaços; f) avaliação processual dos resultados, no âmbito dos diferentes currículos de formação.

Contudo, na prática, a gestão democrática nas IES brasileiras tem se deparado com diversas barreiras, sobretudo as atitudinais no âmbito dos contextos curriculares. É comum identificar-se atitudes de discriminação negativa em relação aos sujeitos em formação e os profissionais com deficiências das diversas áreas do conhecimento. $\mathrm{Na}$ concepção da gestão democrática, contudo, esses não podem ser invisibilizados ou estarem ausentes dessas discussões e reflexões.

Nesse cenário, urgiu a necessidade de se identificar, descrever e analisar elementos que (des)compõem a gestão democrática no processo de diferenciação e acessibilidade curricular em cursos da Educação Superior de uma universidade federal do interior do estado de São Paulo.

Motivados por esses objetivos, o presente artigo visou apresentar os principais resultados de um estudo desenvolvido institucionalmente no âmbito de políticas de ações 
afirmativas e da triangulação de ações de ensino, pesquisa e extensão, na perspectiva da gestão democrática e da acessibilidade.

Para além da busca pela garantia dos direitos humanos, enquanto relevância social, o estudo se justifica pelo propósito de contribuir, acadêmica e cientificamente, com o incitamento de reflexões acerca das condições de ingresso, permanência, formação profissional e transição para o mercado de trabalho, nas quais se envolvam os atores dos contextos das IES e de seus respectivos territórios.

\section{Método}

O presente estudo de caso, de caráter descritivo e qualitativo, configurou-se como uma pesquisa exploratória, de campo, que considerou um contexto de investigação em que elementos e variáveis constituintes de diversos episódios puderam contribuir com a compreensão do fenômeno dessa realidade (GIL, 2008).

\section{Contexto e Participantes da pesquisa}

O campo explorado foi um dos campi de uma universidade pública situada em uma cidade de médio porte do estado de São Paulo, onde são ofertados 33 cursos de graduação (licenciatura e bacharelado).

Para o presente estudo, especificamente, desenvolvido entre o $1^{\circ}$ semestre de 2018 e o $1^{\circ}$ semestre de 2020, foi selecionado um único curso de graduação da instituição por terem sido considerados os seguintes critérios: a) cursos em que estivessem estudantes com deficiências matriculados; b) estudantes com deficiências no início da trajetória acadêmica $\left(1^{\circ}\right.$ ano); c) cursos em que ofertavam Atividades Práticas Curriculares (APC) ${ }^{4}$ ou Estágios Curriculares desde o primeiro semestre de formação acadêmico-profissional; d) concordância da gestão do curso em desenvolver atividades cooperativas de ensino, pesquisa e extensão.

Com base na identificação dos possíveis microcontextos, segundo os referidos critérios, a execução do estudo foi realizada respeitando-se os procedimentos éticos de pesquisas com seres humanos, de acordo com as resoluções $n^{\circ}$ 466/12 e $n^{\circ}$ 510/16 do Conselho Nacional de Saúde (CNS).

Ainda, partindo da premissa da gestão democrática, a pesquisa foi iniciada após a proposta ter sido apresentada, em pauta de conselho do departamento em que o curso está

${ }^{4}$ Carmo, Prado e Barros (2018), definem as Atividades Práticas Curriculares como ações que são feitas em laboratórios, situações-problema, simulando a vivência real do estudante em um ambiente de trabalho.

RPGE- Revista on line de Política e Gestão Educacional, Araraquara, v. 24, n. esp. 2, p. 1104-1117, set. 2020. e-ISSN: 1519-9029 
vinculado, dialogada, esclarecida, votada e aprovada. Com base nos encaminhamentos, concordaram em participar diretamente da pesquisa: quatro professoras; três gestores (coordenador do curso, pró-reitor de graduação e coordenador de assuntos relacionados a ações afirmativas); nove estudantes (P1 a P8, mais o primeiro estudante do curso autodeclarado como pessoa com deficiência física, identificado no presente estudo por Agenor ${ }^{5}$ ).

\section{Procedimentos de coleta, tratamento e análise dos dados}

A coleta de dados foi realizada por meio de: a) observações em full immersion, cujo contexto foi representado por atividades teóricas e práticas do curso; b) entrevistas junto a todos os participantes; e c) análise documental (regimentos, projetos políticos pedagógicos, legislação e correspondências eletrônicas).

Os dados obtidos por diários de campo, filmagens e gravações foram transcritos e organizados na perspectiva da análise de conteúdo, por meio de protocolo desenvolvido especificamente para o estudo e de fichas de análise de vídeos, adaptadas de Menegon (2013). Os indicadores de análise, apresentados a seguir, foram discutidas e validadas em grupo de pesquisa constituído por pessoas com deficiências e sem deficiências, sejam elas docentes, pesquisadoras ou estudantes de graduação e pós-graduação.

\section{Resultados e Discussões}

Os resultados e discussões tangenciaram, na perspectiva da gestão democrática, ações de: planejamento para recursos e estratégias; utilização e desenvolvimento; gerenciamento; avaliação; diferenciação e acessibilidade curricular.

Em uma perspectiva socio-histórico-cultural, no âmbito dessas ações, foi possível identificar e discutir alguns aspectos sobre recursos humanos, materiais, tecnológicos e financeiros; adequações; tempos e espaços; estratégias pedagógicas; competências do alunato; diretrizes curriculares (disciplinas, normativas, diplomação e perspectivas profissionais); boas práticas de acessibilidade; e (des)construção sobre concepções de deficiência e de formação profissional.

\section{Planejamento}

No processo de planejamento, os dados indicaram que é fundamental a cooperação entre os estudantes, docentes, gestores de curso e de setores da instituição, extrapolando-se a cultura

\footnotetext{
${ }^{5}$ Agenor, de 21 anos, possui hemiplegia, que é a paralisia de uma metade do corpo. É, portanto, a sequela de uma
} patologia que pode estar localizada em uma ou algumas áreas do sistema nervoso central.

RPGE- Revista on line de Política e Gestão Educacional, Araraquara, v. 24, n. esp. 2, p. 1104-1117, set. 2020. e-ISSN: 1519-9029 
universitária de fragmentação dos tempos e espaços, dos recursos, metas e práticas, presente em uma ética institucional que, há décadas, tem se mostrado predominantemente cristalizada (BAREMBLIT, 2002; BUTT, 2009; GAMA; FIGUEIREDO, 2009; GALLEGO; SILVA, 2012).

Dentre os diversos aspectos a serem considerados nesse processo, está o de lançar mão de estratégias que identifiquem as concepções de deficiência. Isso porque, segundo Agenor, eram perceptíveis algumas atitudes negativamente discriminantes em relação à deficiência, veladas ou explícitas, por meio de narrativas e/ou ações negativas, sobretudo no início do curso.

Com base nesses dados, foram planejados e fomentados diálogos individuais e coletivos, em classe e extraclasse, sobre concepções de deficiência e formação/atuação profissional. Gradualmente, essas iniciativas possibilitaram ao estudante com deficiência, a seus pares, docentes e gestores, não apenas a identificação de atitudes negativas, mas a materialização de comportamentos de respeito acompanhados pelo reconhecimento em relação às potencialidades do profissional com deficiência em formação.

Concomitantemente a esse processo, os atores envolvidos debruçaram-se, em uma perspectiva cooperativa, sobre o planejamento para a Diferenciação e Acessibilidade Curricular (DAC). Dentre os diversos elementos discutidos, destacou-se o tema referente às competências necessárias para que o alunato do curso fosse considerado apto a exercer sua função como profissional. Como fruto dessas iniciativas, os atores envolvidos destacaram algumas dessas competências:

Quadro 01 - Competências elencadas como fundamentais para um profissional do curso, segundo os participantes desse estudo.

\section{Dimensão teórica}

compreensão cognitiva; comprometimento com os estudos; expressão escrita e narrativa do conhecimento; composição das noções acadêmicas.
Dimensão prática

habilidade de execução; técnica; psicomotricidade fina.
Dimensão da Convivencialidade comunicação compreensível; empatia; ética; proatividade; atitudes positivas; inteligência emocional.

Fonte: Elaboração própria.

À luz desses apontamentos e do próprio contexto de execução do Projeto Pedagógico do Curso (PPC), percebe-se que mesmo que Agenor apresente grande parte das competências como necessárias, foi inquestionável a necessidade de identificação de métodos, estratégias, 
equipamentos, órteses, instrumentário, ergonomia e outros recursos de acessibilidade que visassem a equiparação de oportunidades (BRASIL, 2015).

É nesse sentido que a identificação das características dos estudantes e dos contextos, em uma perspectiva biopsicossocial, seja realizada desde o início dos semestres letivos e em suas respectivas transições. Entende-se que esse processo traz potencial influência, a curto, médio e longo prazo, sobre o planejamento, desenvolvimento e utilização de recursos no âmbito da Diferenciação e Acessibilidade Curricular (DAC).

\section{Desenvolvimento e Utilização}

O desenvolvimento e a utilização de recursos, previstos no planejamento, exigem um contínuo gerenciamento dos tempos e dos espaços, pelos gestores, docentes e discentes ao longo de todo o percurso de ensino-aprendizagem e da formação profissional (MORAIS, 2020).

Nessa dimensão, os dados da presente pesquisa revelam que os diversos atores envolvidos no cenário estudado reconhecem Agenor como parte fundamental (mas não central) dos movimentos de orquestração da cooperação, na perspectiva da acessibilidade, para a realização da DAC.

Essa perspectiva vai ao encontro do movimento "nada sobre nós sem nós", no processo de gestão democrática, em que a ação docente esteja engrenada, administrativa e pedagogicamente, nas esferas práticas e teóricas (DELEUZE; GUATTARI, 1977; GAVÉRIO, 2017).

Foi observado, nesse processo, que o próprio estudante com deficiência cooperou com a orquestração acessibilidade, como parte dela, na perspectiva biopsicossocial. Quando identificadas barreiras no contexto de atuação como, por exemplo, em relação a uma saboneteira, muito necessária em suas atividades, Agenor relata: “a questão é que, para lavar as mãos, tem toda uma técnica correta [...]. Como eu não consigo mover essa mão, [isso] dificulta eu lavar a outra. Mas eu 'meio que' adaptei uma técnica para mim e consegui lavar".

Além desses direcionamentos individuais, o estudo indicou interessantes deslocamentos dos docentes e estudantes com e sem deficiência, representados por atitudes positivas que transversalizaram, gradativamente, as teorias e as práticas no processo de formação profissional dos indivíduos, a saber: a) cuidados com a acessibilidade comunicacional nas práticas pedagógicas; b) diversificação de estratégias de ensino e de técnicas de procedimentos práticos; c) feedbacks e reforço positivo, ao longo da realização das atividades; d) construção de diálogos coletivos entre todos os atores; e) estratégias de avaliação processual a curto, médio e longo prazo. 
Os dados sugerem, portanto, uma superação gradual de barreiras atitudinais dentre os atores envolvidos e, como dizia Freire (1996), onde há vida, há inacabamento e, diante disso, os sujeitos precisam estar abertos a alterações e a ressignificarem-se diante a novos elementos.

Contudo, ressalta-se que, assim como ocorre na Educação Básica, há a necessidade de oportunidades que discutam especificidades das deficiências e temáticas relacionadas a identidades e diferenças tanto na formação inicial dos estudantes, quanto na formação continuada dos docentes, gestores, servidores técnicos e administrativos (MENDES; CIA; CABRAL, 2015).

\section{Gerenciamento}

À luz dos dados identificados, compreendemos que os atores do curso se movimentaram cooperativa e interdisciplinarmente, promovendo parcerias entre demais áreas do conhecimento que, nesta pesquisa, predominou a interrelação entre a Educação Especial, Psicologia, Educação Física, Terapia Ocupacional e Engenharia de Produção.

Para além do gerenciamento do currículo planejado, os resultados das avaliações processuais incitavam possibilidades de desenvolvimento de recursos tecnológicos e ergonômicos, tanto em caráter consultivo, quanto deliberativo, com a participação direta e constante do próprio gestor do curso e, muitas das vezes, dos próprios estudantes com e sem deficiência.

Concomitantemente a esses processos, foram identificados elementos fundantes do gerenciamento no âmbito de diálogos, indagações, (des)construção de concepções de deficiência(s) e da mobilização coletiva para o conhecimento da legislação que versa sobre o cidadão com deficiência identificados. Isso representou um caráter participativo na elaboração de encaminhamentos necessários para a equiparação de oportunidades (VIEIRA, 2007; GELATTI; MARQUEZAN, 2013).

\section{Avaliação}

Sobre os processos avaliativos, no âmbito da DAC, tanto o gestor, quanto os docentes e colegas de classe concordaram com a possibilidade de adequação avaliativa, sobretudo quando identificadas possibilidades de consequências negativas em seu desempenho, em decorrência da ausência ou insuficiência das adequações.

Isso porque, no caso em questão, considerar no processo de avaliação as habilidades manuais, motoras, psicomotoras, e de execução, sem ponderar que o estudante é uma pessoa com deficiência, se configuraria como negligência e omissão (por não adequar as estratégias de 
ensino e de avaliação) e discriminação negativa com base na deficiência, crimes tipificados pelo Estatuto da Pessoa com Deficiência (BRASIL, 2015).

Por outro lado, o processo de adequação da avaliação culminou em questionamentos por parte dos atores do curso acerca da diplomação dos estudantes com deficiência. O que deveria ser diferenciado: o diploma ou o currículo?

Visando compreender a concepção dos participantes em relação a essa questão, apresentamos suas narrativas (Quadro 02).

Quadro 02 - Fatos e Opiniões contra e a favor de uma diferenciação no diploma.

\begin{tabular}{|c|c|c|}
\hline $\begin{array}{c}\text { Fatos sobre a diferenciação } \\
\text { no diploma }\end{array}$ & $\begin{array}{l}\text { Opiniões contra uma } \\
\text { diferenciação no diploma }\end{array}$ & $\begin{array}{l}\text { Opiniões a favor de uma } \\
\text { diferenciação no diploma }\end{array}$ \\
\hline $\begin{array}{l}\text { - O diploma específico atesta } \\
\text { que Agenor tem capacidades } \\
\text { para atuar profissionalmente } \\
\text { trabalhar em certos campos, } \\
\text { mas não em outros; } \\
\text { - O diploma comum é um } \\
\text { direito de todos os cidadãos; } \\
\text { - A diferenciação no diploma } \\
\text { é discriminatória e antiética. }\end{array}$ & $\begin{array}{l}\text { - “(...) ele passou no curso de } \\
\text { [nome do curso] e passou pelos } \\
\text { mesmos estágios de avaliação do } \\
\text { que eu, talvez adaptados, mas } \\
\text { passou pelos mesmos estágios de } \\
\text { avaliação do que eu”" (P5); } \\
\text { - Não, não precisa. Se precisar de } \\
\text { alguma declaração, que venha à } \\
\text { parte; } \\
\text { - Um diploma diferenciado } \\
\text { estigmatizaria; } \\
\text { - No mercado de trabalho, essa } \\
\text { diferenciação pode se tornar um } \\
\text { mecanismo para difundir o } \\
\text { preconceito; } \\
\text { - Não é porque ele (Agenor) é } \\
\text { diplomado para fazer } \\
\text { [procedimento específico do } \\
\text { curso], no mercado de trabalho, } \\
\text { que ele o fará, necessariamente; } \\
\text { - As barreiras podem ser dirimidas } \\
\text { no próprio mercado de trabalho; } \\
\text { - Nem todas as capacidades que o } \\
\text { curso exige para uma diplomação } \\
\text { serão necessárias no mercado de } \\
\text { trabalho. }\end{array}$ & $\begin{array}{l}\text { - Com a diferenciação no } \\
\text { diploma já prevista, as pessoas } \\
\text { com deficiência(s) poderiam } \\
\text { seguir a área que querem, se } \\
\text { isentarem de algumas áreas e se } \\
\text { especializarem e outras; } \\
\text { - Se não é mesmo possível o } \\
\text { Agenor fazer, por exemplo, } \\
\text { [um procedimento], sim, sou a } \\
\text { favor que o diploma seja } \\
\text { diferenciado. }\end{array}$ \\
\hline
\end{tabular}

Fonte: Elaborado pelos autores a partir dos discursos dos participantes.

A não clareza sobre esse aspecto, por entre os atores do contexto, trouxe a Agenor o sentimento de que ele poderia estar se esforçando sem propósitos concretos, diferentemente de todos os seus colegas de classe. Foi evidente o impacto desses dissensos sobre sua motivação em permanecer no curso, causando-lhe inquietações intrapessoais sobre seu planejamento pessoal, projeto de vida e formação profissional (CABRAL, 2013). O debate foi tão intenso e 
complexo, que Agenor ressaltou: "antes de qualquer adequação curricular, quero saber se, no mínimo, tinha o direito de ser diplomado".

Percebendo esse processo e compreendendo que a DAC precisaria ser planejada no âmbito da instituição, a coordenação do curso envolveu os pesquisadores, a pró-reitoria de graduação e o setor responsável pelas questões de direitos humanos da instituição, com vistas a se concretizar a gestão democrática na perspectiva da acessibilidade.

\section{Construindo a Diferenciação e Acessibilidade Curricular na Educação Superior}

O cenário apresentado previamente culminou em ações institucionais para assegurar que as trajetórias de formação acadêmica e profissional aos estudantes com deficiência(s) não fossem transpassadas por atitudes de discriminação negativa, negligência e omissão.

Nesse sentido, foi encaminhada uma consulta oficial à Procuradoria Federal da instituição, com o objetivo de se obter orientações baseadas na legislação brasileira que respaldassem não somente o ingresso de estudantes com deficiência, mas suas respectivas trajetórias acadêmicas, participação, aprendizagem, formação/habilitação profissional, diplomação, transição para o mercado de trabalho e orientação aos seus projetos de vida.

Após cuidadosa análise, a pró-reitoria de graduação encaminhou à gestão do curso um parecer da Procuradoria Federal, que reconheceu serem legais quaisquer propostas que tenham a finalidade de adequar o currículo de discentes com deficiências na Educação Superior.

Sua orientação foi a de que a proposta de DAC fosse construída pelo Núcleo Docente Estruturante (NDE) do curso, de acordo com as demandas apresentadas por seus professores e estudantes. Posteriormente, a proposta deveria ser aprovada pelo Conselho de Curso e encaminhada para a Divisão de Desenvolvimento Pedagógico da Pró-Reitoria de Graduação da instituição explorada, para análise sob o ponto de vista da legislação e normativas internas. Finalmente, a proposta deveria ser encaminhada para o CoG. Todos esses procedimentos foram concretizados.

Essa decisão e encaminhamentos, frutos da presente pesquisa e da cooperação de todos os atores envolvidos, dialogam diretamente com o Estatuto da Pessoa com Deficiência. Nessa perspectiva, compreende-se que esses deslocamentos contribuíram com o rompimento de uma cristalização institucional, trazendo subsídios ao exercício dos direitos cidadãos e liberdades fundamentais desta população, particularmente nas esferas da educação, da saúde, da profissionalização, da habilitação, da auto advocacia, do empreendedorismo e do trabalho.

A Diferenciação e Acessibilidade Curricular, se adotada na perspectiva da gestão democrática, da cooperação e da acessibilidade, poderá fomentar o desenvolvimento das 
potencialidades, talentos, habilidades e aptidões físicas, cognitivas, sensoriais, psicossociais, atitudinais, profissionais e artísticas dos sujeitos envolvidos. No que tange aos indivíduos com deficiência, particularmente, tem a potencialidade de contribuir com a conquista de sua autonomia e participação social, segundo suas características, interesses e necessidades de aprendizagem, no âmbito da Educação Superior (BRASIL, 2015).

\section{Considerações finais}

A orquestração entre os atores para o desenvolvimento e implementação da Diferenciação e Acessibilidade Curricular na Educação Superior, na perspectiva da Gestão Democrática, poderá contribuir com encaminhamentos institucionais que promovam condições de equidade de oportunidades aos estudantes universitários com deficiências, superando-se atitudes de discriminação negativa e de negligência, por ação ou omissão.

O estudo sugere, ainda, que a formação profissional perpassa pelo reconhecimento das identidades e diferenças apresentadas por estudantes com e sem deficiências, em todos os cursos das IES. É necessário, portanto, vislumbrar-se a potência de as experiências quotidianas culminarem em avanços pedagógicos, científicos e tecnológicos, em articulação intersetorial na implementação, inclusive, de políticas públicas, institucionais e departamentais.

À luz da gestão democrática, o respaldo jurídico resultante da presente pesquisa cooperativa e seus dados analisados, abrem um precedente histórico que poderá subsidiar as IES brasileiras que se atentem para a legitimação do direito de estudantes com deficiências se formarem profissionalmente e concretizarem seus respectivos projetos de vida.

Contudo, cabe questionar e resistir às latentes ameaças atualmente representadas por decisões dos poderes legislativo, executivo e judiciário. A democracia de nosso país e a autonomia das IES brasileiras, de seus respectivos setores e atores têm sido colocadas em risco, bem como a própria concretização do princípio de gestão democrática orquestrada na perspectiva da acessibilidade.

AGRADECIMENTOS: Ao Programa Universal CNPq (processo $n^{\circ}$ 431096/2016-3) e ao Programa Institucional de Bolsas de Iniciação Científica Conselho Nacional de Desenvolvimento Científico e Tecnológico (PIBIC/CNPq).

\section{REFERÊNCIAS}


AGUIAR, M. C. C. Um olhar sobre desafios da gestão didático-pedagógica no Ensino Superior. Pro-Posições, Campinas, v. 27, n. 3, p. 221-236, 2016. Disponível em:

http://www.scielo.br/scielo.php?script=sci_arttext\&pid=S0103-

$73072016000300221 \&$ lang=pt. Acesso em: 10 abr. 2020.

ARAÚJO, A. C. A gestão democrática e os canais de participação dos estudantes. Revista Retratos da Escola, Brasília, v. 3, n. 4, p. 253-266, jan./jun. 2009. Disponível em:

http://retratosdaescola.emnuvens.com.br/rde/article/download/116/305. Acesso em: 0 maio 2020.

BAREMBLIT, G. Compêndio de análise institucional e outras correntes: teoria e prática. 5. ed. Belo Horizonte, MG: Instituto Felix Guatarri. 2002.

BORDIGNON, G.; GRACINDO, R. V. Gestão da educação: o município e a escola. In: FERREIRA, N. S. C. (org.). Gestão da educação: impasses, perspectivas e compromissos. São Paulo: Cortez, 2000. p. 147-176.

BRASIL. Lei n. 13.146, de 06 de julho de 2015. Institui a Lei Brasileira de Inclusão da pessoa com deficiência. Brasília, DF: Casa Civil, 2015. Disponível em:

http://maragabrilli.com.br/wp-content/uploads/2016/03/Guia-sobre-a-LBI-digital.pdf. Acesso em: 15 fev. 2020.

BUTT, G. O planejamento de aulas bem sucedidas: fatores chave do planejamento de aula. 2. ed. Rio de Janeiro: Editora SBS, 2009.

CABRAL, L. S. A. Orientação acadêmica e profissional dos estudantes universitários com deficiência: perspectivas internacionais. 2013. 212 f. Tese (Doutorado em Educação Especial) - Universidade Federal de São Carlos, São Carlos. 2013.

CABRAL, L. S. A. Políticas de ações afirmativas, pessoas com deficiência e o reconhecimento das identidades e diferenças no ensino superior brasileiro. Archivos Analíticos de Políticas Educativas/Education Policy Analysis Archives, Arizona State University v. 26, 2018.

CARMO, L.; PRADO, R. R.; BARROS, T. Possibilidades para inclusão e acessibilidade de uma pessoa cega no curso de nutrição da UFPA. In: CONGRESSO BRASILEIRO DE EDUCAÇÃO ESPECIAL, 8., 2018, São Carlos. Proceedings [...]. Campinas, SP: Galoá, 2018. Disponível em: https://proceedings.science/cbee/cbee-2018/papers/possibilidades-parainclusao-e-acessibilidade-de-uma-pessoa-cega-no-curso-de-nutricao-da-ufpa. Acesso em: 19 maio 2020.

DELEUZE, G.; GUATTARI, F. Kafka por uma literatura menor. Rio de Janeiro: Imago, 1977.

EBERSOLD, S. Ecole inclusive, Société de la connaissance et Impératif d'accessibilité. Carnets Rouges, n. 18, 2020.

FREIRE, P. Pedagogia da autonomia: saberes necessários à prática educativa. 25. ed. São Paulo: Paz e Terra, 1996. 
FUSARI, J. C. O. Planejamento do trabalho pedagógico: algumas indagações e tentativas de respostas. 1998. Disponível em: http://www.smec.salvador.

ba.gov.br/site/documentos/espaco-virtual/espacopraxispedagogicas/ GEST \%C3\%830/o\%20 planejamento \%20do\%20trabalho.pdf. Acesso em: 28 maio 2020.

GAMA, A. D. S.; FIGUEIREDO, S. A. de. O planejamento no contexto escolar. WebRevista Discursividade Estudos Linguísticos, Nova Andradina, n. 4, 2009.

GAVÉRIO, M. A. Nada sobre nós, sem nossos corpos! O local do corpo deficiente nos Disability Studies. Revista Argumentos, Montes Claros, v. 14, n. 1, p. 95-117, 2017.

GELATTI, L.D.; MARQUEZAN, L. I. P. Contribuições da gestão escolar para a qualidade da educação. Revista de Gestão e Avaliação Educacional, Santa Maria, v. 2, n. 4, p. 43-62, 2013.

GIL, A. C. Métodos e técnicas de pesquisa social. 6. ed. São Paulo: Atlas, 2008.

KRAWCZYK, N. A gestão escolar: um campo minado... Análise das propostas de 11 municípios brasileiros. Educação e Sociedade, Campinas, v. 20, n. 67, p. 112-149, 1999.

KRAWCZYK, N. R.; VIEIRA, V. L. Homogeneity and heterogeneity on education systems in Argentine, Brazil, Chile and Mexico. Cadernos de Pesquisa, São Paulo, v. 36, n. 129, p. 673-704, 2006.

LIBÂNEO, J. C. A organização e a gestão da escola: teoria e prática. Goiânia: Alternativa, 2007.

LIMA, A. H.; CABRAL, L. S. A. Tecnologias, Recursos Humanos, Orientação Acadêmica e Profissional de Universitários com Deficiência. In: CONGRESSO DE INICIAÇÃO CIENTÍFICA, 25.; CONGRESSO DE INICIAÇÃO EM DESENVOLVIMENTO TECNOLÓGICO E INOVAÇÃO, 10., 2018, São Carlos. Anais [...]. São Carlos, 2018.

LÜCK, H. Gestão educacional: uma questão paradigmática. Petrópolis: Vozes, 2007.

MACHADO, C. M. F.; CORTE, M. G. D. Fortalecimento dos conselhos escolares no cenário da gestão democrática da rede municipal de ensino de Santa Maria - RS. Revista IberoAmericana de Estudos em Educação, Araraquara, v. 15, n. 2, p. 522-538, fev. 2020. Disponível em: https://periodicos.fclar.unesp.br/iberoamericana/article/view/12093. Acesso em: 10 jun. 2020.

MENDES, E. G.; CIA, F.; CABRAL, L. S. A. (org.). Inclusão Escolar e os Desafios para a Formação de Professores em Educação Especial. 1. ed. São Carlos: Marquezine \& Manzini - ABPEE, 2015. v. 1. 530 p.

MENEGON, É. N. Imagens e narrativas midiáticas: análise dos vídeos do YouTube. 2020. 152 f. Dissertação (Mestrado) - Universidade Estadual Paulista, Marília, 2020. 
MORAIS, E. S. Tecnologia instrucional em educação especial: uma revisão integrativa da literatura (2008 - 2018). 2020. 123 f. Dissertação (Mestrado em Educação Especial) Universidade Federal de São Carlos, São Carlos, 2020.

MORENO, J. C. Conceito de minorias e discriminação. Revista USCS, São Caetano do Sul, v. 10, p. 141-156. dez. 2009.

OLIVEIRA, I. C.; VASQUES-MENEZES, I. Revisão de literatura: o conceito de gestão escolar. Cadernos de Pesquisas, São Paulo, v. 48, n. 169, p. 876-900, 2018.

VIEIRA, S. L. Gestão, avaliação e sucesso escolar: recortes da trajetória cearense. Estudos Avançados, São Paulo, v. 21, n. 60. 2007.

\section{Como referenciar este artigo}

LIMA, A. H.; CABRAL, L. S. A. Gestão democrática na educação superior para a diferenciação e acessibilidade curricular. Revista on line de Política e Gestão Educacional, Araraquara, v. 24, n. esp. 2, p. 1104-1117, set. 2020. e-ISSN: 1519-9029. DOI: https://doi.org/10.22633/rpge.v24iesp2.14336

Submetido em: $30 / 04 / 2020$

Revisões requeridas em: $26 / 06 / 2020$

Aprovado em: 30/07/2020

Publicado em: 30/09/2020 